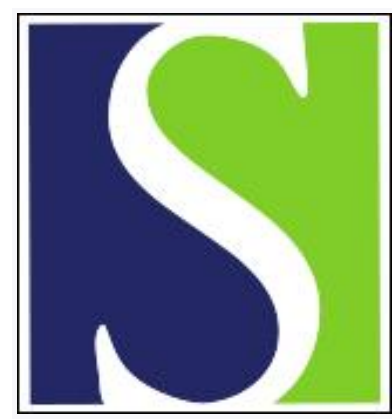

Scand J Work Environ Health 2011;37(1):37-44

https://doi.org/10.5271/sjweh.3123

Published online: 01 Oct 2010, Issue date: Jan 2011

Long-term effects of biomechanical exposure on severe knee pain in the Gazel cohort

by Descatha A, Cyr D, Imbernon E, Chastang J-F, Plenet A, Bonenfant S, Zins M, Goldberg M, Roquelaure Y, Leclerc A

Affiliation: Unité de pathologie professionnelle, CHU Poincaré, 104 bd Poincaré, 92380 Garches, France. alexis.descatha@rpc.aphp.fr

Refers to the following texts of the Journal: 1996;22(3):165-175

2006;32(4):294-299

The following articles refer to this text: $2012 ; 38(6): 568-576$;

2012;38(6):485-488

Key terms: biomechanical exposure; cohort; exposure; Gazel cohort; knee; knee pain; long-term effect; occupational factor

This article in PubMed: www.ncbi.nlm.nih.gov/pubmed/20886201

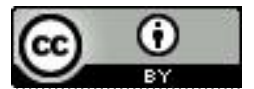




\section{Long-term effects of biomechanical exposure on severe knee pain in the Gazel cohort}

by Alexis Descatha, MD, PhD, 1, 2, 3 Diane Cyr, MA, , 2 Ellen Imbernon, MD, PhD, ${ }^{4}$ Jean-François Chastang, PhD, ${ }^{1}$ Aurélia Plenet, MSc, ${ }^{1,2}$ Sébastien Bonenfant, MSc, ${ }^{1,2}$ Marie Zins, MD, ${ }^{1,2}$ Marcel Goldberg, MD, PhD, ${ }^{1,4}$ Yves Roquelaure, MD, PhD, ${ }^{5}$ Annette Leclerc, $P h D^{1,2}$

Descatha A, Cyr D, Imbernon E, Chastang J-F, Plenet A, Bonenfant S, Zins M, Goldberg M, Roquelaure Y, Leclerc A. Long-term effects of biomechanical exposure on severe knee pain in the Gazel cohort. Scand J Work Environ Health. 2011;37(1):37-44.

Objective Little is known about the long-term effect of occupational determinants on knee pain. We aimed to assess whether the risk factors for severe knee pain, observed with a cross-sectional approach, were still relevant after retirement, 12 years later.

Methods All men participating in the ARPEGE side study of the GAZEL cohort (employees of the French national utility for energy production and distribution, recruited in 1989) and who answered the 1994 or 1995 general GAZEL self-administered questionnaire, were included. Weight and self-reported exposures over the entire working life were collected at baseline. Knee pain and its intensity were recorded in 1994-1995 and again in 2006. Moderate and severe knee pain, defined from an intensity or discomfort scale (threshold 3 on a 6-level scale in 1994-1995, and 4 on an 8-level scale in 2006), were the main outcomes.

Results At baseline, 1786 men were included. In 1994-1995, moderate knee pain was observed among 10.3\% and severe pain in $12.8 \%$ of men. In 2006, 1482 men (83\%) answered the questionnaire. Moderate and severe knee pain were observed in $18.6 \%$ and $16.3 \%$ of respondents, respectively. Working in a kneeling or squatting position was significantly associated with severe knee pain at baseline, taking into account age, sports, smoking habits, and body mass index [adjusted odds ratio $\left(\mathrm{OR}_{\text {adj }}\right) 1.4,95 \%$ confidence interval $(95 \% \mathrm{CI}) 1.1-1.9$ for "ever exposed" and $\mathrm{OR}_{\text {adj }} 2.0$, 95\% CI 1.3-3.1 for $>25$ years of exposure]. In 2006, when most subjects were retired, the association between working in a kneeling or squatting position and severe pain was weaker but still significant ( $\left.\mathrm{OR}_{\mathrm{adj}} 1.4,95 \% \mathrm{CI} 1.04-1.85\right)$.

Conclusions The effect of high knee exposure in the working life on severe knee pain remains even after retirement, although decreased. An extended surveillance and prevention program for these workers could be proposed.

Key terms cohort; long-term effect; occupational factor.

Knee pain is a relatively common condition and a cause of disability in the general population $(1,2)$. A Canadian population-based study in a working population aged 18-65 years, found a 9.6\% prevalence of knee complaint among men (8.6\% in both genders) (3), whereas in another population-based study among 6641 men and women with median age 78.8 years, the knee pain prevalence was $35.2 \%$ (4). In a working populationbased study among 1404 men, 28\% of the subjects had suffered from knee pain in the last year (5). In a Finnish study among 2122 workers from a forestry company (white and blue-collar workers), who were free of knee pain, a $10 \%$ incidence was observed during the one-year follow-up (6). According to a systematic review, knee pain prevalence in the previous 12 months ranged from $11.2-60.9 \%$, depending on the age of the population and the risk factors studied (7).

Knee pain can arise from various disorders including osteoarthritis (OA), meniscus disorders, or tendonitis (2). Some reviews (8-12) have summarized the known

1 Inserm U1018, Centre for research in Epidemiology and Population Health, Epidemiology of occupational and social determinants of health, Villejuif, France

2 University of Versailles St-Quentin, UMRS 1018, Villejuif, France

3 AP-HP, Poincaré University Hospital, Occupational Health Department, Garches, France

4 Department of Occupational Health, National Institute for Public Health Surveillance (InVS), St-Maurice, France

5 Laboratory of Epidemiology and Ergonomics and Occupational Health, University of Angers, Angers, France

Correspondence to: Dr Alexis Descatha, Unité de pathologie professionnelle, CHU Poincaré, 104 bd Poincaré, 92380 Garches, France. [E-mail: alexis.descatha@rpc.aphp.fr] 
risk factors of OA of the knee, including occupational factors; there is evidence that some occupational exposures, especially kneeling and squatting, are risk factors for $\mathrm{OA}$

Considering these elements and the natural history of knee OA, we could hypothesize that the occupational determinant of OA are involved not only in actual knee pain, but also long afterward, even after retirement. However, most prior studies concerned OA, and we found no study on the long-term effects of occupational factors on knee pain.

We studied a subsample of men from the GAZEL cohort (ARPEGE side study) to see if known occupational factors associated with severe knee pain at baseline, were still relevant 12 years later.

\section{Methods}

\section{Sample}

The GAZEL cohort was established in 1989. Its members are volunteers recruited among the employees of Electricité de France (EDF) and Gaz de France (GDF), the French national utility for energy production and distribution. The company employs approximately 150000 people of diversified trades and socioeconomic status throughout France. At baseline in 1989, the cohort included 20625 volunteers, men then aged 40-50 and women $35-50$ years. In January of each year (including 1994, 1995, and 2006), participants receive a general questionnaire about their lifestyle, health, and occupational situation. In addition, more than 40 sub-projects explore specific themes, some using additional specific questionnaires (13).

The ARPEGE side study was designed to analyze musculoskeletal disorders of the upper and lower limbs. In 1994-1995, a sample was selected among
GAZEL participants, including all blue- and whitecollar workers, half of the managers, and one quarter of the supervisors. In our study, we included only the men from the ARPEGE side study who answered the 1994 or the 1995 general GAZEL self-administered questionnaire (see figure 1). Women were not included in these analyses because of the low prevalence of their exposure to biomechanical factors.

\section{Exposure and covariates}

In 1994-1995 (baseline), all included subjects filled out both the annual GAZEL and the specific ARPEGE self-administered questionnaires. The following were recorded: age, body mass index [continuous variable and divided into three categories: $<25 \mathrm{~kg} / \mathrm{m}^{2}$ (normal), $\geq 25 \mathrm{~kg} / \mathrm{m}^{2}$ (excess weight), $\geq 30 \mathrm{~kg} / \mathrm{m}^{2}$ (obese)], regular practice of sports (yes/no), and current smoker (yes/no).

Self-assessed lifetime occupational exposures for knees were also recorded: "working in a kneeling position", "working in a squatting position", "carrying loads while bending knees", "holding loads on shoulder", "working in confined spaces", "climbing a support structure" (four different variables about the use of climbers), "walking $>2$ hours/day", "walking on rough/ hilly ground", "climbing on stairs, ladders, stepladders or standing on ladders $>1 / 2$ hour per day" (several different variables). Highly correlated variables were aggregated together: kneeling with squatting and walking $>2$ hours with walking on rough/hilly ground. Based on a preliminary analysis, in our study we included only the factor most strongly associated with severe knee pain in 1994-1995 (ie, "working in a kneeling or a squatting position"). Three categories were considered, based on duration of exposure: (i) "never exposed" (or $<1$ year), (ii) $1-25$ years, and (iii) $\geq 25$ years. Taking into account the specificity of the cohort (homogeneity of duration of exposure if exposed), workers were also classified into "never" or "ever exposed" ( $\geq 1$ year of exposure).

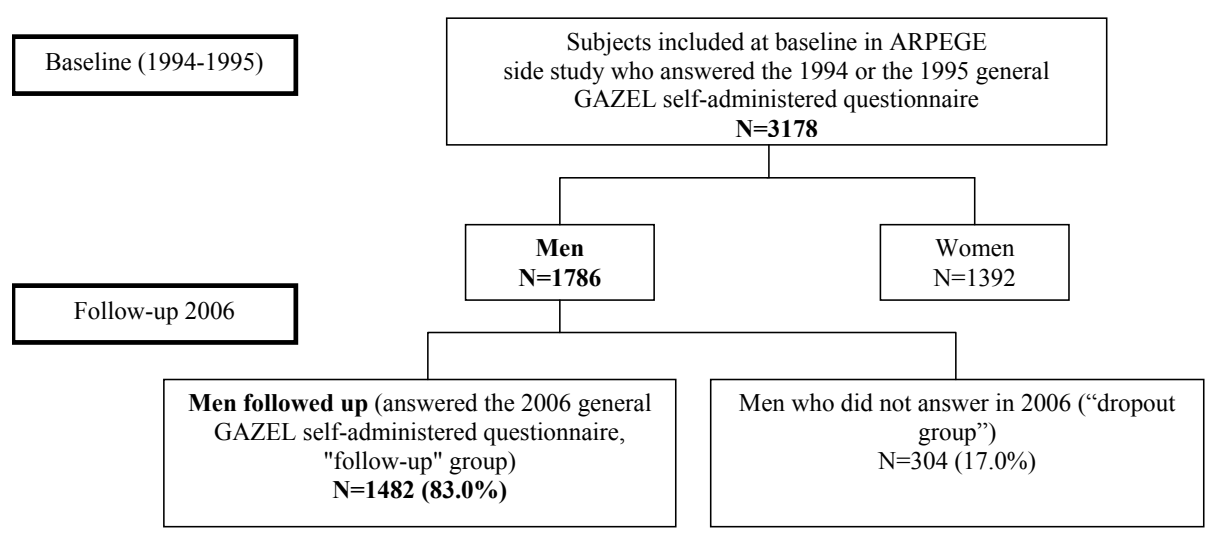

Figure 1. Flowchart of study process 
Information about socioprofessional group was recorded in 1989, divided in 11 categories, such as bluecollar workers, technical supervisors, managers, etc. Since age at retirement is relatively young in France and especially at Electricité de France and Gaz de France, most of the subjects had retired by 2006 .

\section{Outcome variables}

The main outcome variable considered in this study was severe knee pain in the previous year, defined at baseline in the ARPEGE self-administered questionnaire as pain or discomfort of $>3$ on a 6-level scale (one question). In the 2006 GAZEL self-administered questionnaire, severe knee pain was defined as pain or discomfort of $>4$ on an 8-level scale. Problems in the daily life associated with knee troubles, such as difficulties in walking or climbing stairs, were recorded. The subjects also recorded the cause of the knee pain (OA, meniscus, tendonitis, other).

\section{Analysis}

Associations between occupational or personal factors and severe knee pain at baseline (cross-sectional analyses) were described using bivariate analyses (chisquare test). Multivariate analyses were performed using logistic regressions. In order to differentiate moderate from severe knee pain, a three-category variable was also considered using multinomial logistic regression models. The association between factors present at baseline in 1994-1995 and severe knee pain 12 years later in 2006 (longitudinal analyses) was assessed using similar models. Another variable ("having retired before 1 January 2001") was added to take into account early retirement. Finally, restricted analyses were performed, including only subjects without severe pain at baseline and without any knee pain. Statistical analysis software, version 9.1 (SAS Institute Inc, Cary, NC, USA) was used for all statistical analyses. Associations were considered statistically significant if $\mathrm{P}<0.05$.

\section{Results}

\section{Baseline results}

In 1994-1995, 1786 men, aged 47-51 years, answered the GAZEL and ARPEGE questionnaires (figure 1) and constituted the baseline sample. Of these, $10.3 \%$ $(\mathrm{N}=183)$ had moderate knee pain and $12.8 \%(\mathrm{~N}=228)$ severe knee pain; $54.7 \%(\mathrm{~N}=976)$ of subjects had a body mass index $\geq 25 \mathrm{~kg} / \mathrm{m}^{2}$ [including $9.1 \%$ ( $\mathrm{N}=163$ ) with a body mass index $\geq 30 \mathrm{~kg} / \mathrm{m}^{2}$, table 1]. Kneeling and/or squatting exposure was found mostly

Table 1. The association between knee pain in 1994-1995 and personal and occupational factors assessed in 1994-1995 (bivariate analyses). [SD=standard deviation; $\mathrm{OR}=0 \mathrm{dds}$ ratio; $95 \% \mathrm{Cl}=95 \%$ confidence interval.]

\begin{tabular}{|c|c|c|c|c|c|c|c|c|c|c|c|c|c|c|c|}
\hline & \multicolumn{3}{|c|}{ Total } & \multicolumn{6}{|c|}{ Moderate knee pain } & \multicolumn{6}{|c|}{ Severe knee pain } \\
\hline & Mean & $\mathrm{SD}$ & $\mathrm{N}$ & Mean & SD & $\mathrm{N}$ & $\%$ & $\begin{array}{c}\text { OR } \\
\text { (crude) }\end{array}$ & $95 \% \mathrm{Cl}$ & Mean & $\mathrm{SD}$ & $\mathrm{N}$ & $\%$ & $\begin{array}{c}\text { OR } \\
\text { (crude) }\end{array}$ & $95 \% \mathrm{Cl}$ \\
\hline Age (years) a & 48.84 & 1.38 & & 48.84 & 1.43 & & & 1.00 & $0.90-1.12$ & 48.86 & 1.38 & & & 1.02 & $0.92-1.13$ \\
\hline \multicolumn{16}{|l|}{ Active smoker } \\
\hline No & & & 1386 & & & 138 & 9.96 & 1.00 & & & & 182 & 13.13 & 1.00 & \\
\hline Yes & & & 400 & & & 45 & 11.25 & 1.13 & $0.79-1.61$ & & & 46 & 11.50 & 0.87 & $0.62-1.23$ \\
\hline \multicolumn{16}{|l|}{ Excess weight } \\
\hline $\mathrm{BMI}<25 \mathrm{~kg} / \mathrm{m}^{2}$ & & & 810 & & & 86 & 10.62 & 1.00 & & & & 84 & 10.37 & 1.00 & \\
\hline BMI $25-30 \mathrm{~kg} / \mathrm{m}^{2}$ & & & 813 & & & 83 & 10.21 & 1.00 & $0.73-1.38$ & & & 112 & 13.78 & 1.38 & $1.02-1.87^{b}$ \\
\hline $\mathrm{BMI} \geq 30 \mathrm{~kg} / \mathrm{m}^{2}$ & & & 163 & & & 14 & 8.59 & 0.89 & $0.49-1.62$ & & & 32 & 19.63 & 2.08 & $1.33-3.28^{b}$ \\
\hline \multicolumn{16}{|l|}{ Regular sports } \\
\hline No & & & 1075 & & & 99 & 9.21 & 1.00 & & & & 145 & 13.49 & 1.00 & \\
\hline Yes & & & 711 & & & 84 & 11.81 & 1.30 & $0.95-1.77$ & & & 83 & 11.67 & 0.87 & $0.65-1.17$ \\
\hline \multicolumn{16}{|l|}{$\begin{array}{l}\text { Working in a } \\
\text { kneeling or a }\end{array}$} \\
\hline$<1$ year & & & 1094 & & & 113 & 10.33 & 1.00 & & & & 116 & 10.60 & 1.00 & \\
\hline $1-25$ & & & 506 & & & 61 & 12.06 & 1.26 & $0.90-1.76^{b}$ & & & 74 & 14.62 & 1.49 & $1.08-2.04^{b}$ \\
\hline$\geq 25$ & & & 186 & & & 9 & 4.84 & 0.50 & $0.25-1.001$ & & & 38 & 20.43 & 2.04 & $1.36-3.07^{b}$ \\
\hline Total & & & 1786 & & & 183 & 10.3 & & & & & 228 & 12.8 & & \\
\hline
\end{tabular}

${ }^{a}$ Age as a continuous variable (and $O R$ associated with an increase of one year).

b $P<0.05$ 
among blue-collar workers and technical supervisors $(\mathrm{N}=495 / 679,72.9 \%$ versus $184 / 679,27.1 \%$ for the other categories, $\mathrm{P}<0.0001)$. The highest prevalence of severe knee pain was observed among the blue-collar workers' socioprofessional group $(18.8 \%, \mathrm{~N}=66)$.

Regular practice of a sport or being an active smoker were not statistically associated with knee pain in 19941995 (table 1). A body mass index $\geq 25 \mathrm{~kg} / \mathrm{m}^{2}$ was associated with knee pain [crude odds ratio (OR) for severe knee pain of $1.50,95 \%$ confidence interval $(95 \%$ CI) 1.13-2.00]. Kneeling and/or squatting (ever versus never in working life) was significantly associated with knee pain, especially severe knee pain. After adjusting for age, body mass index and regular sports, exposure to kneeling and/or squatting (ever versus never in working life) also remained significantly associated with severe knee pain at baseline (simple logistic model 1, table 2). From the simple logistic model 2 and the multinomial model using three categories for duration of exposure, a dose-response relationship was observed (table 2).

\section{Dropouts during follow-up}

Among responders in 1994-1995, 304 men (17.0\%) did not answer the 2006 questionnaire (hereafter the "dropout group"). The other men were followed up until 2006 (ie, "follow-up group"). These subjects declared more often having been exposed to kneeling and/or squatting in their working life than those in the dropout group: the proportion of subjects exposed to kneeling and/or squatting was $40.9 \%(\mathrm{~N}=606)$ in the follow-up group, versus $28.3 \%(\mathrm{~N}=86)$ in the dropout group $(\mathrm{P}<0.0001)$. Being overweight was also more frequent in the follow-up group [58.4\% $(\mathrm{N}=865)$ versus $36.5 \%(\mathrm{~N}=111)$, respectively, $\mathrm{P}<0.0001]$. However, the prevalence of severe knee pain at baseline was not significantly different between the two groups [13.2\% $(\mathrm{N}=196)$ in the follow-up group versus $10.5 \%(\mathrm{~N}=32)$ among dropouts, $\mathrm{P}>0.05]$, and the mean age was not statistically different between the two groups [48.8 years, standard deviation (SD) 1.3 in the two groups, $\mathrm{P}>0.05]$.

\section{Evolution between 1994-1995 and 2006}

Among the 1482 men in the follow-up group, the prevalence of severe knee pain in 2006 was higher than at baseline [16.3\% $(\mathrm{N}=241)$ versus $13.2 \%(\mathrm{~N}=196)$, dropouts not taken into account, figure 2]. The mean age of this group was 60.8 years (range 59-63 years) and 98\% had retired $[55.7 \%(\mathrm{~N}=826)$ men retired before 1 January 2001]. The prevalence of knee pain (severe and nonsevere) was also higher than at baseline $[34.8 \%(\mathrm{~N}=516)$ versus $23.9 \%(\mathrm{~N}=354)$ dropouts not taken into account].

Among the 196 men in the follow-up group who had severe knee pain in 1994-1995, 33.7\% (N=66) also had severe knee pain in 2006 (figure 2).

In $2006,12.4 \%(\mathrm{~N}=183)$ of subjects reported they suffered from OA of the knee; $49.7 \%(\mathrm{~N}=91)$ of them had

Table 2. Association between moderate and severe knee pain in 1994-1995 and personal and occupational factors assessed in 1994-1995 (multivariate analyses). [OR=0dds ratio; $95 \% \mathrm{Cl}=95 \%$ confidence interval.]

\begin{tabular}{|c|c|c|c|c|c|c|c|c|}
\hline & \multirow{2}{*}{\multicolumn{2}{|c|}{$\begin{array}{l}\text { Simple logistic model } 1^{\mathrm{a}} \\
\text { Severe knee pain versus } \\
\text { no or moderate knee pain }\end{array}$}} & \multirow{2}{*}{\multicolumn{2}{|c|}{$\begin{array}{l}\text { Simple logistic model } 2^{\mathrm{b}} \\
\text { Severe knee pain versus } \\
\text { no or moderate knee pain }\end{array}$}} & \multicolumn{4}{|c|}{ Multinomial logistic model } \\
\hline & & & & & \multicolumn{2}{|c|}{$\begin{array}{l}\text { Moderate knee pain versus } \\
\text { no knee pain }\end{array}$} & \multicolumn{2}{|c|}{$\begin{array}{l}\text { Severe knee pain versus } \\
\text { no knee pain }\end{array}$} \\
\hline & $\mathrm{OR}^{\mathrm{c}}$ & $95 \% \mathrm{Cl}$ & $\mathrm{OR}^{\mathrm{c}}$ & $95 \% \mathrm{Cl}$ & $\mathrm{OR}^{\mathrm{c}}$ & $95 \% \mathrm{Cl}$ & $\mathrm{OR}^{\mathrm{c}}$ & $95 \% \mathrm{Cl}$ \\
\hline Age (years) d & 1.01 & $0.91-1.12$ & 1.01 & $0.90-1.12$ & 0.99 & $0.88-1.11$ & 1.01 & $0.90-1.12$ \\
\hline \multicolumn{9}{|l|}{ Active smoker } \\
\hline No & 1.00 & & 1.00 & & 1.00 & & 1.00 & \\
\hline Yes & 0.83 & $0.57-1.21$ & 0.83 & $0.57-1.21$ & 0.99 & $0.66-1.47$ & 0.83 & $0.57-1.21$ \\
\hline $\begin{array}{l}\text { Body mass index } \\
\left(\mathrm{kg} / \mathrm{m}^{2}\right)^{d}\end{array}$ & $1.09 \mathrm{e}$ & $1.04-1.14$ & 1.09 e & $1.04-1.14$ & 0.98 & $0.93-1.04$ & 1.08 & $1.04-1.13$ \\
\hline \multicolumn{9}{|l|}{ Regular sports } \\
\hline No & 1.00 & & 1.00 & & 1.00 & & 1.00 & \\
\hline Yes & 0.93 & $0.68-1.26$ & 0.93 & $0.68-1.26$ & 1.19 & $0.86-1.66$ & 0.95 & $0.70-1.29$ \\
\hline \multicolumn{9}{|c|}{$\begin{array}{l}\text { Working in a kneeling } \\
\text { or a squatting position }\end{array}$} \\
\hline$<1$ year & 1.00 & & 1.00 & & 1.00 & & 1.00 & \\
\hline $1-25$ years & $1.63^{e}$ & $1.22-2.19$ & $1.50 \mathrm{e}$ & $1.08-2.07$ & 1.22 & $0.86-1.73$ & $1.54 \mathrm{e}$ & $1.11-2.14$ \\
\hline$\geq 25$ years & $\cdot$ &.. & $2.02^{e}$ & $1.34-3.10$ & 0.53 & $0.26-1.07$ & $1.90 \mathrm{e}$ & $1.23-2.94$ \\
\hline
\end{tabular}

a Model 1: working in a kneeling or a squatting position <1 year ("never exposed", reference group) was compared to >1 year ("ever exposed").

b Model 2: working in a kneeling or a squatting position <1 year ("never exposed", reference group) was compared to 1-25 years and $\geq 25$ years.

${ }^{c}$ Adjusted for age, smoking habits (active smoker versus not), body mass index, and regular sports (yes versus no).

d Continuous variable.

e $P<0.05$. 


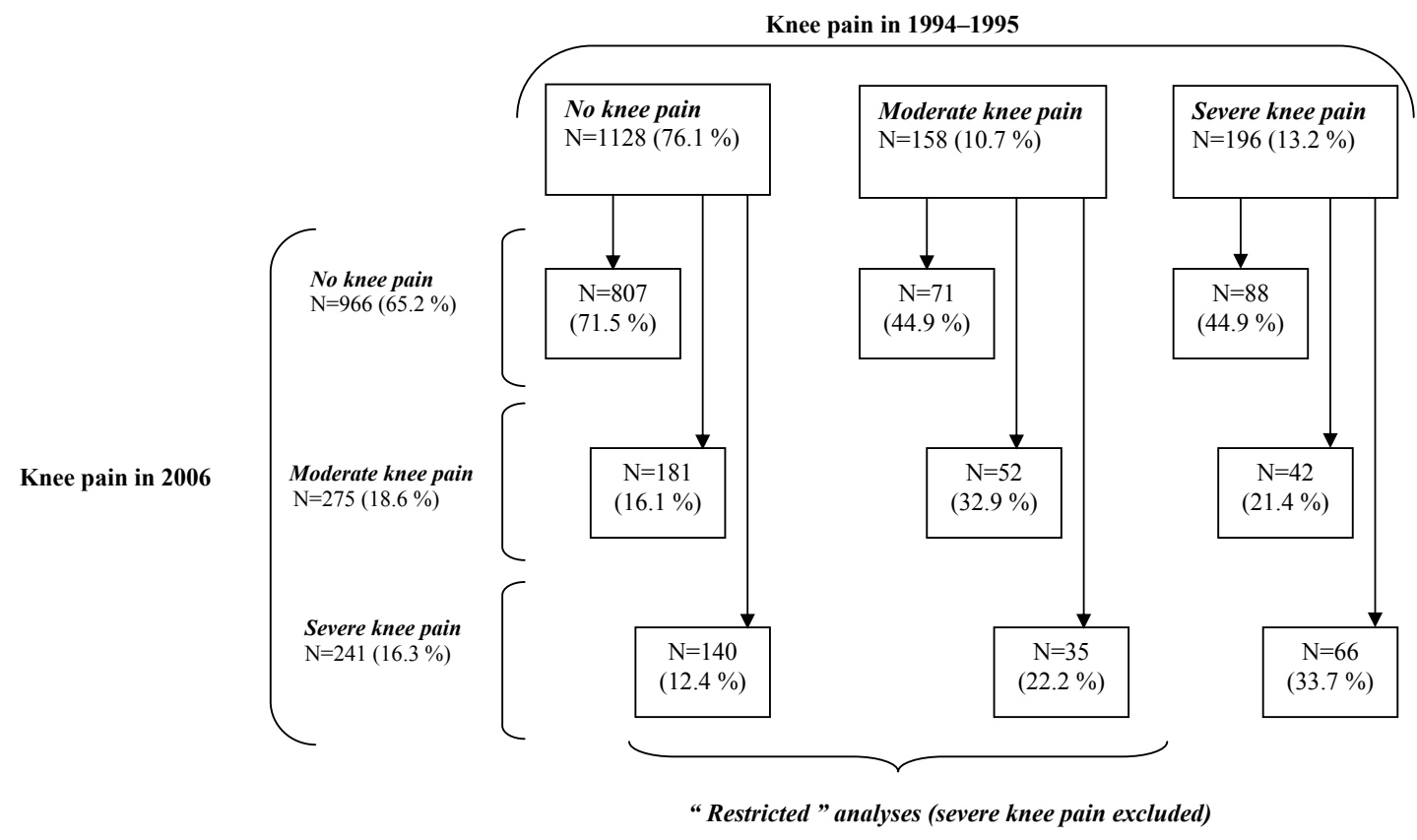

Figure 2. Evolution of the knee pain ("follow up" group only, $\mathrm{N}=1482$ )

severe knee pain. Other reported disorders were meniscus problems and knee tendonitis for 108 and $66 \mathrm{men}$, respectively. In 2006, 21.2\% ( $\mathrm{N}=51)$ of men with severe knee pain had difficulties climbing stairs because of their knee problem [versus $1.5 \%(\mathrm{~N}=19)$ for men without severe knee pain, $\mathrm{P}<0.0001]$ and $11.2 \%(\mathrm{~N}=27)$ had difficulties walking [versus $1.3 \%(\mathrm{~N}=16), \mathrm{P}<0.0001$ ].

The prevalence of severe knee pain between men who retired before 1 January 2001 and those who retired later was not statistically significant $(15.1 \%$ versus $13.1 \%, \mathrm{P}>0.05)$.

\section{Association between the baseline variables and severe knee pain in 2006}

Kneeling and/or squatting reported in 1994-1995 were still significantly associated with severe knee pain in 2006, taking into account the same confounding factors as in the previous analyses and time of retirement (table 3 , simple logistic model 1). However, the strength of the association was weaker and the year of retirement has a slight but not significant effect on severe knee pain. The dose-response relationship was no longer observed (simple logistic model 2 and multinomial model, table 3).

\section{Analyses restricted to workers without severe knee pain and no pain at all}

In analyses restricted to men who did not report severe knee pain in 1994-1995 ( $\mathrm{N}=1286)$, the adjusted OR $\left(\mathrm{OR}_{\mathrm{adj}}\right)$ for kneeling and/or squatting were similar in the three logistic models: (i) significant for ever exposed in the simple model 1 ( $\mathrm{OR}_{\mathrm{adj}} 1.44,95 \%$ CI $\left.\left.1.03-2.01\right]\right)$, (ii) significant for 1-25 years of exposure in the simple model $2\left(\mathrm{OR}_{\mathrm{adj}} 1.55\right.$ 95\% CI 1.09-2.22), and (iii) significant for 1-25 years of exposure and severe knee pain in the multinomial model $\left(\mathrm{OR}_{\text {adj }} 1.51,95 \%\right.$ CI 1.05-2.17).

Analyses restricted to men who did not report any knee pain at all in 1994-1995 ( $\mathrm{N}=1128)$, showed similar associations, except for the simple model 1 where the association was borderline for significance $\left(\mathrm{OR}_{\mathrm{adj}} 1.45\right.$, 95\% CI 0.996-2.10, $\mathrm{P}=0.053$ ).

\section{Discussion}

Knee biomechanical exposure in working life, more precisely kneeling and/or squatting, was associated with severe knee pain in this study, taking into account personal confounders (age, body mass index, smoking habits). This association was weaker 12 years later but remained significant. Analyses restricted to men without pain at baseline (or with moderate pain) gave similar results. However, different limitations can be discussed.

Selection effects must be discussed. No statistical difference in severe (or moderate) knee pain at baseline was observed between the two groups (ie, follow-up and dropout), even though the lifetime prevalence of exposure to biomechanical factors was higher in the followup group. Selection effects at inclusion and attrition 
Table 3. Association between moderate and severe knee pain in 2006, and personal and occupational factors assessed in 1994-1995 (multivariate analyses) [OR=odds ratio; $95 \% \mathrm{Cl}=95 \%$ confidence interval.]

\begin{tabular}{|c|c|c|c|c|c|c|c|c|}
\hline & \multirow{2}{*}{\multicolumn{2}{|c|}{$\begin{array}{l}\text { Simple logistic model 1a } \\
\text { Severe knee pain versus } \\
\text { no or moderate knee pain }\end{array}$}} & \multirow{2}{*}{\multicolumn{2}{|c|}{$\begin{array}{l}\text { Simple logistic model } 2^{\mathrm{b}} \\
\text { Severe knee pain versus } \\
\text { no or moderate knee pain }\end{array}$}} & \multicolumn{4}{|c|}{ Multinomial logistic model } \\
\hline & & & & & \multicolumn{2}{|c|}{$\begin{array}{l}\text { Moderate knee pain versus no } \\
\text { knee pain }\end{array}$} & \multicolumn{2}{|c|}{$\begin{array}{l}\text { Severe knee pain versus no } \\
\text { knee pain }\end{array}$} \\
\hline & $\mathrm{OR}^{\mathrm{c}}$ & $95 \% \mathrm{Cl}$ & $\mathrm{OR}^{\mathrm{c}}$ & $95 \% \mathrm{Cl}$ & $\mathrm{OR}^{\mathrm{c}}$ & $95 \% \mathrm{Cl}$ & $\mathrm{OR}^{\mathrm{c}}$ & $95 \% \mathrm{Cl}$ \\
\hline Age (years) d & 0.98 & $0.87-1.10$ & 0.98 & $0.87-1.10$ & 1.00 & $0.89-1.12$ & 0.98 & $0.87-1.10$ \\
\hline \multicolumn{9}{|l|}{ Active smoker } \\
\hline No & 1.00 & & 1.00 & & 1.00 & & 1.00 & \\
\hline Yes & 1.02 & $0.71-1.46$ & 1.02 & $0.71-1.46$ & 1.15 & $0.82-1.63$ & 1.05 & $0.73-1.52$ \\
\hline $\begin{array}{l}\text { Body mass index } \\
\left(\mathrm{kg} / \mathrm{m}^{2}\right)^{d}\end{array}$ & $1.08 \mathrm{e}$ & $1.03-1.13$ & $1.08 \mathrm{e}$ & $1.03-1.13$ & 1.02 & $0.98-1.07$ & $1.09 \mathrm{e}$ & $1.04-1.14$ \\
\hline \multicolumn{9}{|l|}{ Regular sports } \\
\hline No & 1.00 & & 1.00 & & 1.00 & & 1.00 & \\
\hline Yes & 1.14 & $0.85-1.53$ & 1.14 & $0.84-1.53$ & 1.04 & $0.78-1.39$ & 1.15 & $0.85-1.55$ \\
\hline \multicolumn{9}{|c|}{$\begin{array}{l}\text { Working in a kneeling } \\
\text { or a squatting position }\end{array}$} \\
\hline$<1$ year & 1.00 & & 1.00 & & 1.00 & & 1.00 & \\
\hline $1-25$ years & $1.38^{e}$ & $1.04-1.85$ & $1.45^{e}$ & $1.06-1.97$ & 0.87 & $0.63-1.19$ & $1.40^{e}$ & $1.02-1.92$ \\
\hline$\geq 25$ years & . & .. & 1.20 & $0.74-1.94$ & 1.06 & $0.67-1.68$ & 1.22 & $0.74-2.00$ \\
\hline \multicolumn{9}{|c|}{$\begin{array}{l}\text { Retired before } 1 \text { January } \\
2001\end{array}$} \\
\hline No & 1.00 & & 1.00 & & 1.00 & & 1.00 & \\
\hline Yes & 0.74 & $0.54-1.02$ & 0.75 & $0.54-1.03$ & 1.03 & $0.75-1.42$ & 0.75 & $0.54-1.04$ \\
\hline
\end{tabular}

a Model 1: working in a kneeling or a squatting position $<1$ year ("never exposed", reference group) was compared to $>1$ year ("ever exposed").

${ }^{b}$ Model 2: working in a kneeling or a squatting position < 1 year ("never exposed", reference group) was compared to $1-25$ years and $\geq 25$ years.

${ }^{c}$ Adjusted for age, smoking habits (active smoker versus not), body mass index, regular sports (yes versus no) and retirement before 1 January 2001.

d Continuous variable.

e $\mathrm{P}<0.05$.

during the follow-up have been studied previously in the GAZEL cohort: the initial participation of men in the whole GAZEL cohort was mostly influenced by lifestyle characteristics such as alcohol consumption and by health or cultural factors, while dropouts were mostly explained by the occurrence of major health problems $(14,15)$. The prevalence of knee pain was similar to that found in a one-year prospective study among workers of a large Finnish forestry company, where 23\% suffered from knee pain at baseline [mean age 45 years, predominantly men (6)], and similar to prevalence of knee pain in the last year (28\%) in a working population-based study of 1404 men (5).

Other potential selection effects came from the specificity of the GAZEL cohort. The physical workload of this cohort corresponds mainly to electric distribution maintenance. This physical exposure is different from what can be observed in other activities (construction industry for instance), with more postural constraints such as kneeling and/or squatting than for instance handling and/or carrying loads while bending knees or manual materials handling in general. Workers also kept their job for a long time, with an inter-quartile range of 10-25 years of exposure for most of the biomechanical exposure self-assessed in the cohort. Hence the variability in exposure was limited. All these elements could explain why there is no clear dose-response relationship, especially for the long-term approach, in addition to the probable decrease with time of the strength of the association. Finally, one last particularity was the early age of retirement in the cohort, from 55-65 years old in EDF-GDF.

The fact that the exposure was self-reported must also be discussed: a recent review about lowerextremity musculoskeletal disorders and occupational mechanical factors concluded that better exposure assessment is needed to examine causal pathways (16). The authors observed that in epidemiological studies on knee pain, exposure was most often self-reported. Jensen's review on OA (12) also reported the poor description of exposure. However, the description of the lifetime exposure associated with the socioprofessional group in the Gazel cohort suggested that the selfreport exposure was probably accurate. The validity of lifetime occupational exposure (versus current) is also questionable (17). However, taking into account the stability of the exposure in the cohort, if a recall bias exists, it is probably limited. The validity of self-report of weight and height has been previously studied in the whole GAZEL cohort (18): there was a small but statistically significant underestimation of the body mass index $\left(0.29 \mathrm{~kg} / \mathrm{m}^{2}\right.$ on average). Self-reported outcome 
is the most appropriate measure when studying pain or discomfort. We chose "severe" pain or discomfort as a major outcome, with a threshold at the middle of the scale, as recommended by guidelines on chronic pain (19). High intensity of pain and presence of disability are closely correlated, especially for patients with symptoms rating over the $50 \%$ threshold (19). Knee pain can result from different conditions, including both knee and hip disorders, and we have no information on the medical care of the patients with knee disorders. However, we observed that almost half of the subjects reported they had knee OA in 2006.

The results were adjusted for age, body mass index, smoking habits, and regular sports. Being overweight is known to be associated with OA (20-23). Manek et al (24) studied the association between body mass index, OA and genetic factors; they concluded that the strong association between excess weight and knee OA is not likely to be mediated by shared genetic factors. Our study also contributed to the observation that body mass index is a risk factor for knee pain independent of occupational exposure. Sport, which is known to be a risk factor for knee OA (11), was not significantly associated with severe knee pain or discomfort in our study. However, information about sports practice was partial and this variable was mostly used for adjustment purposes. We could also discuss that in the 12 years of the follow-up, changes in non-occupational exposure might have occurred. For instance, the subjects may have experienced new sports and other leisure activities involving the knee, such as gardening. Nevertheless, the level of exposure in these leisure activities is expected to be lower than for occupational factors. It is also probable that in this time period, no other workers have been newly exposed to occupational biomechanical constraints.

The kneeling or squatting position was chosen in order to study the long-term effect of biomechanical exposure for the knee, taking into account preliminary analyses. It is also one of the known occupational factors associated with OA (8-12), especially in association with other constraints $(12,25-27)$. Baker et al (5) found that symptomatic men whose work entailed kneeling or squatting were more likely to be referred to an orthopedic surgeon than the average population ( $28 \%$ or $31 \%$ versus $24 \%$ ). Miranda et al (6) found, in a one-year follow-up study, that risk factors relevant for self-reported knee pain seemed to be highly similar to those involved in knee OA reported in other studies, especially age, being overweight, knee-straining work, as well as previous knee injury and smoking. However, the association between work-related factors and the incidence of knee pain was rather weak, with an adjusted OR of 1.6 (95\% CI 1.0-2.4) for working with the trunk flexed forward, in standing or kneeling position, for
$0.5-1$ hour a day. Working in a kneeling position was too closely correlated with squatting to be studied separately in this cohort. Other occupational biomechanical risk factors (climbing stair/ladders, extensive walking) could have been chosen for this study. However, taking into account the specificity of the population, the strong association between exposures, the preliminary analyses, and the aim of the study, we decided to focus on kneeling and/or squatting. Psychosocial factors were not studied given that there is insufficient evidence to conclude to a relationship between knee disorders and these factors (28).

The main purpose of our study was to analyze the long-term determinants of severe knee pain, especially the role of kneeling or squatting. Our results tend to confirm that the factors associated with severe knee pain might be risk or aggravating factors even in the long term. Even though residual confounding bias is always possible, this should emphasize the need for the surveillance of workers highly exposed to knee constraints. In terms of prevention, these results suggest that losing weight and limiting occupational exposure could be appropriate, especially taking into account the persistence of the effect 12 years later, and after retirement. However, the strength of the association was moderate $(\mathrm{OR}>2)$ with a decrease in the strength of association with time and possibly also with retirement. Further studies are needed, conducted in populations including both genders, more heterogeneous for the knee's exposure, with a more precise assessment of past exposure. In future long-term studies, particular attention should be paid to the medical diagnoses to differentiate pain related to degenerative disorders (OA with information on the joint involved, chronic meniscus disorders, etc) from others (sprain or acute tendonitis for instance).

\section{Acknowledgments}

The authors express their thanks to EDF-GDF, especially to the Service Général de Médecine de Contrôle and to the Caisse centrale d'action sociale du personnel des industries électrique et gazière. We also wish to acknowledge the cohort team of the Unité mixte 687-1018 Inserm responsible for the GAZEL database management. The GAZEL cohort study was funded by EDF-GDF and the French National Institute of Health and Medical Research (INSERM) and received grants from the Cohortes Santé TGIR Program. This study is part of the workage project supported by the French National Research Agency (ANR), and by the French Agency for Environmental and Occupational Health Safety (AFSSET). 


\section{References}

1. Cooper C, Coggon D. Physical activity and knee osteoarthritis. Lancet 1999;353(9171):2177-2178.

2. Belo JN, Berger MY, Koes BW, Bierma-Zeinstra SM. Prognostic factors in adults with knee pain in general practice. Arthritis Rheum 2009;61(2):143-151.

3. Messing K, Tissot F, Stock S. Distal lower-extremity pain and work postures in the Quebec population. Am J Public Health 2008;98(4):705-713.

4. Arden NK, Crozier S, Smith H, Anderson F, Edwards C, Raphael $\mathrm{H}$ et al. Knee pain, knee osteoarthritis, and the risk of fracture. Arthritis Rheum 2006;55(4):610-615.

5. Baker P, Reading I, Cooper C, Coggon D. Knee disorders in the general population and their relation to occupation. Occup Environ Med 2003;60(10):794-797.

6. Miranda H, Viikari-Juntura E, Martikainen R, Riihimaki H. A prospective study on knee pain and its risk factors. Osteoarthritis Cartilage 2002;10(8):623-630.

7. Cozzensa da Silva M, Fassa AG, Rodrigues DM, Kriebel D. Gonalgia entre trabalhadores e fatores ocupacionais associados: Uma revisão sistemática [Knee pain and associated occupational factors: a systematic review]. Cad Saude Publica 2007;23(8):1763-1775.

8. Cooper C. Occupational activity and the risk of osteoarthritis. J Rheumatol Suppl 1995;43:10-12.

9. Kirkeskov Jensen L, Eenberg W. Occupation as a risk factor for knee disorders. Scand J Work Environ Health 1996;22(3):165-175.

10. Maetzel A, Makela M, Hawker G, Bombardier C. Osteoarthritis of the hip and knee and mechanical occupational exposure--a systematic overview of the evidence. J Rheumatol 1997;24(8):1599-1607.

11. Vignon E, Valat JP, Rossignol M, Avouac B, Rozenberg S, Thoumie $\mathrm{P}$ et al. Osteoarthritis of the knee and hip and activity: a systematic international review and synthesis (OASIS). Joint Bone Spine 2006;73(4):442-455.

12. Jensen LK. Knee osteoarthritis: influence of work involving heavy lifting, kneeling, climbing stairs or ladders, or kneeling/ squatting combined with heavy lifting. Occup Environ Med 2008;65(2):72-89.

13. Goldberg M, Leclerc A, Bonenfant S, Chastang JF, Schmaus A, Kaniewski N et al. Cohort profile: the GAZEL Cohort Study. Int J Epidemiol 2007;36(1):32-39.

14. Goldberg M, Chastang JF, Leclerc A, Zins M, Bonenfant S, Bugel I et al. Socioeconomic, demographic, occupational, and health factors associated with participation in a longterm epidemiologic survey: a prospective study of the French GAZEL cohort and its target population. Am J Epidemiol 2001;154(4):373-384.
15. Goldberg M, Chastang JF, Zins M, Niedhammer I, Leclerc A. Health problems were the strongest predictors of attrition during follow-up of the GAZEL cohort. J Clin Epidemiol 2006;59(11):1213-1221.

16. D'Souza JC, Franzblau A, Werner RA. Review of epidemiologic studies on occupational factors and lower extremity musculoskeletal and vascular disorders and symptoms. J Occup Rehabil 2005;15(2):129-165.

17. Miranda H, Gold JE, Gore R, Punnett L. Recall of prior musculoskeletal pain. Scand J Work Environ Health 2006;32(4):294-299.

18. Niedhammer I, Bugel I, Bonenfant S, Goldberg M, Leclerc A. Validity of self-reported weight and height in the French GAZEL cohort. Int $\mathrm{J}$ Obes Relat Metab Disord 2000;24(9):1111-1118.

19. French National Authority for Health (HAS). Douleur chronique: reconnaître le syndrome douloureux chronique, l'évaluer et orienter le patient [Chronic pain: recognition, evaluation and orientation]. 2008 [cited 9 May 2010.] Available from: http:// www.has-sante.fr/portail/upload/docs/application/pdf/2009 01/douleur_chronique_argumentaire.pdf.

20. Coggon D, Reading I, Croft P, McLaren M, Barrett D, Cooper C. Knee osteoarthritis and obesity. Int J Obes Relat Metab Disord 2001;25(5):622-627.

21. Holmberg S, Thelin A, Thelin N. Knee osteoarthritis and body mass index: a population-based case-control study. Scand J Rheumatol 2005;34(1):59-64.

22. Sturmer T, Gunther KP, Brenner H. Obesity, overweight and patterns of osteoarthritis: the Ulm Osteoarthritis Study. J Clin Epidemiol 2000;53(3):307-313.

23. Rogers MW, Wilder FV. The association of BMI and knee pain among persons with radiographic knee osteoarthritis: a crosssectional study. BMC Musculoskelet Disord 2008;9:163.

24. Manek NJ, Hart D, Spector TD, MacGregor AJ. The association of body mass index and osteoarthritis of the knee joint: an examination of genetic and environmental influences. Arthritis Rheum 2003;48(4):1024-1029.

25. Coggon D, Croft P, Kellingray S, Barrett D, McLaren M, Cooper C. Occupational physical activities and osteoarthritis of the knee. Arthritis Rheum 2000;43(7):1443-1449.

26. Amin S, Goggins J, Niu J, Guermazi A, Grigoryan M, Hunter DJ et al. Occupation-related squatting, kneeling, and heavy lifting and the knee joint: a magnetic resonance imaging-based study in men. J Rheumatol 2008;35(8):1645-1649.

27. Seidler A, Bolm-Audorff U, Abolmaali N, Elsner G. The role of cumulative physical work load in symptomatic knee osteoarthritis - a case-control study in Germany. J Occup Med Toxicol 2008;3(1):14.

28. Macfarlane GJ, Pallewatte N, Paudyal P, Blyth FM, Coggon D, Crombez G et al. Evaluation of work-related psychosocial factors and regional musculoskeletal pain: results from a EULAR Task Force. Ann Rheum Dis 2009;68(6):885-891.

Received for publication: 30 July 2010 